SAND75-0616

Unlimited Release

\title{
Filament Formation on Printed Wiring Boards
}

Charles W. Jennings

Prepared by Sandia Laboratories. Albuquerque New Mexico 87115

and Livermore. Calltornia 94650 for the United States Energy Research

and Devalopment Administration under Contract AT (29.1) 789

Printed December 1975

\section{Sandia Laboratories}

When printing a copy of any digitized SAND Report, you are required to update the markings to current standards. 
Issued by Sandia Laboratories, operated for the United States Energy Research and Development Administration by Sandia Corporation.

\section{NOTICE}

This report was prepared as an account of work sponsored by the United States Government. Neither the United States nor the United States Energy Research and Development Administration, nor any of their employees, nor any of their contractors, subcontractors, or their employees, makes any warranty, express or implied, or assumes any legal liability or responsibility for the accuracy, completeness or usefulness of any information, apparatus, product or process disclosed, or represents that its use would not infringe privately owned rights. 
SAND75-0616

Unlimited Release

FILAMENT FORMATION ON PRINTED WIRING BOARDS

C. W. Jennings

Passive Components Div. 2153

Sandia Laboratories

Albuquerque, New Mexico:87115

December 1975

ABSTRACT

Available information on filaments grown as whiskers and by electromigration on printed wiring boards is reviewed and means for preventing or minimizing their effect are listed. New data is presented on filaments grown by electromigration under condensing moisture conditions. Early studies showed silver migration to be a problem when electrical systems were operated with silver conductors in high humidity environments. It has been demonstrated here that typical printed wiring board conductors (without silver) can develop filaments in minutes with dc potentials as low as 3 volts when there is a visually observable moisture path between the conductors. Leakage resistances from such filaments have been found to be several decades lower than those normally observed for boards in high relative humidities without bulk moisture. Ionic residues aid but are not necessary for filament growth. Coatings are helpful in preventing filament formation but they cannot offer complete protection unless they are free from pinholes, scratches and other defects. Enclosing boards or electronic assemblies in plastic bags has been effective in preventing fllament formation during thermal cycling.

Printed in the United States of America

Available from

National Technical Information Service

U. S. Department of Commerce

5285 Port Royal Road

Springfield, VA 22151 
CONTENTS

$\underline{\text { Page }}$

Introduction 3

Whisker Formation 4

Electromigration 7

Leakage Resistance $\quad 14$

Conclusions 20

References 23

$\begin{array}{ll}\text { Figures } & 26-34\end{array}$

LIST OF FIGURES

$\underline{\text { Page }}$

Figure 1 Tin Whisker growth on a tin plated surface. 26

Figure 2 Filament growths formed between copper 27 conductors $.75 \mathrm{~mm}$ apart on a PWB with a drop of deionized water and 3 volts de for 30 seconds.

Figure 3 Filament growths between solder coated and leveled copper conductors with 20 volts dc for 1 to 2 minutes.

Figure 4 Filament growth interrupted before bridge was formed from cathode to anode over $5 \mathrm{~mm}$ separation.

Figure 5 Growths formed between gold on nickel tabs 30 on a PWB.

Figure 6 Filament grown on PWB under condensing 31 moisture conditions with 20 volts, $.25 \mathrm{~mm}$ separation.

Figure 7 Filaments grown between solder wires on 32 Tefion substrate.

Figure 8 Filament growth from intentional scratches in urethane coated PWB, 20 volts, $1.25 \mathrm{~mm}$ separation.

Figure 9 Filament growth from defects in urethane coating on PWB conductors, 20 volts, $0.38 \mathrm{~mm}$ separation. 


\section{INTRODUCTION}

Malfunction of electronic assemblies from electric current leakage caused by filament bridges between printed wiring board (PWB) conductors has been of concern to design engineers for many years. As circuit functions have become more sophisticated and conductor spacings reduced to accommodate greater circuit densities these concerns have assumed greater importance. This is especially true for PWBs which must perform reliably under diverse environmental conditions.

There are two general types of filament bridges which have been observed to grow between PWB conductors: whiskers grown from tin coatings, and filaments formed by electromigration. These are readily differentiated from bridges formed from slivers broken off from conductor edge overhang, and from those formed in electroplating from resist breakdown. The filaments are typically less than $0.01 \mathrm{~mm}$ in diameter and can be readily burned out with high currents or fractured by mechanical disturbances. However their presence or possible formation especially in low power circuits provides a continuing threat to board functionality.

In this report information is presented on filament formation along with suggested means for eliminating or minimizing its effect on board functionality. Insulation resistance data of coated and uncoated PWBs in high humidity is presented for comparison with resistances measured during and after filament formation. 
WHISKER FORMATION

Whisker growth on tin plated electrical equipment has been known for over 20 years. (1) The formation and nature of these growths have

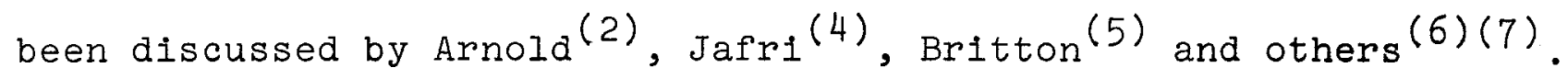
Whisker formation also occurs on zinc and cadmium substrates but most of the investigations have been on tin which is a more frequently used coating material for electronic systems.

Tin whiskers are hairlike single crystal growths of the metal which reach lengths of 1 to $2 \mathrm{~mm}$ and diameters of 1 to $3 \mu \mathrm{m}$. A typical growth is shown in Figure 1. Exceptional growths have reached lengths of $4-5 \mathrm{~mm}$ and diameter of $5 \mu \mathrm{m}$. They grow from the base and may even penetrate insulating coatings. Their elastic and plastic properties were reported by Herring and Galt (7A). Formerly whiskers were not of sufficient length to cause pronounced circuit bridging and were frequently burned off by circuit currents. However with the advent of closely spaced circuitry and the use of low currents one must reevaluate their threat for tin coated PWBs.

Tin whisker formation is widespread and numerous incidents of welectric equipment failures have been attributed to their formation. However, not all tin plated surfaces grow whiskers. The growths have often been sporadic and many inconsistencies have been reported for groups of tin plated specimens which were prepared in a similar manner. For example, apparently similar coatings of tin on steel have shown both whisker growths within a year and also freedom from growths for over 12 years. The observed growths were frequently seen on special areas such as edges or rusted spots. Tin whisker growth does not depend on environment as they have been grown in vacuum, air, 
nitrogen with and without moisture and oil. (6) The growth rate is only moderately sensitive to temperature.

A brass substrate under a tin coating is most conducive to Whisker growth. Other substrates in decreasing order of their tendency to promote whisker growth are electrodeposited copper, sheet copper, steel, electrodeposited nickel, electrodeposited lead, and tin-nickel. Roughness or surface condition of the substrate did not appear to have an appreciable effect on whisker growth, nor did thermal expansivity differences between substrate and coating. Coating thickness influenced growth rate with enhanced growth being associated with thinner coatings. Key ${ }^{(3)}$ pointed out that whiskers grown on a typical sample may represent as much as 15 to 20 percent of the volume of the plated finish. Thus whiskers can produce a measurable reduction in the average thickness of the plated coating. Whisker growth rates have been related to plating conditions and bath types. A bright plated tin for example produces whiskers at a greater rate than matt plated tin. Growths from chemical replacement coatings have also been reported. Flow melted or hot dipped tin coatings are not likely to produce whiskers unless there is an external stress applied to the coating. Alloy deposits such as tin-lead or tin-nickel appear to be far less susceptible to whisker growths than pure tin.

The driving force for whisker growth is attributed to internal stress in the coating or to an externally applied stress. The fact that thinner tin coatings are more susceptible to whiskers than thicker coatings is associated with the decrease in lattice strain 
with increasing tin coating thickness. It has been pointed out that the metals, tin, zinc and cadmium, whose whisker crystals are morphologically similar, are also the finishes which are typically deposited with high intrinsic compressive stress. (3) Other common finishes are deposited with tensile or low stresses. It is also known that changes in plating procedure can change the stress developed in a deposited film.

Britton (5) concluded from his study that complete immunity from whisker growth could not be promised for any pure tin coating but the risk could be greatly reduced by a number of possible measures. Some alloy coatings were found to closely approach and may reach immunity. The suggested measures applicable to PWBs are summarized below:

1. Operate the electroplating bath with recommended operating conditions, using special care for bright tin coatings.

2. Coating thicknesses which are not flow melted should be at least $8 \mu \mathrm{m}$.

3. Heat treat coatings after plating to 180 to $200^{\circ} \mathrm{C}$ for one hour with care taken to avoid blistering of bright tin coatings. When loss of solderability is a problem a controlled atmosphere should be used.

4. Avoid corrosive atmospheres in storage or service.

5. Whenever possible use a tin-lead or tin-nickel coating or a hot dipped or flow melted tin coating.

6. When a mechanical joint or electrical connection is made by means that produce local pressure, some form of insulating collar around the joint should be used. 
7. Use thick layers of resin or introduce a solid insulating barrier between the points in danger of short circuit.

\section{ELECTROMIGRATION}

Electromigration for this report is defined as the electrolytic transfer of metal from one conductor to another conductor which is separated from it by a dielectric medium through which the ions move under de potential. The process is similar to electroplating except the deposited metal builds up in dendritic form from cathode to anode instead of forming a uniform cathodic coating. When the dendritic growth touches the anode, there is an abrupt rise in current corresponding to the formation of an electronic or metallic conducting bridge. With silver and some other noble metals the metallic ions generated at the anode may be reduced by light or other constituents in the medium before reaching the cathode. There is then a stained region of colloidal metal deposits extending from the vicinity of the anode to the cathode. These deposits usually contribute little to the observed conductivity. The dielectric medium is usually a moisture film on a polymer or ceramic surface but could be a moisture saturated undercured polymer. In porous or fibrous materials migration tends to follow the pore or fiber surface and may occur in paths through such materials. In nonporous materials migration is restricted to the surface.

The formation of low resistance paths between conductors by electromigration has also been known for over 20 years and numerous instances have been reported of electric failures or circuit 
malfunctions from such paths. Probably other instances of failure from electromigration have occurred but were not recognized and reported as such. Often reports cite only evidence of corrosion or corrosive residues.

Most of the early studies were concerned with silver migration. Mention was made that migration occurred with other metals but the rates were very much less than for silver. Kohman, Hermance and Downes $(8)$ concluded from their studies that silver migration is a possibility which must be considered whenever silver conductors under dc potential are separated by insulating materials capable of adsorbing moisture. Silver dendritic growths were attributed to the anodic oxidation of silver to a nonpassivating oxide which is sufficiently soluble to form silver ions which migrate to the cathode in the moisture film. Silver deposits of a colloidal character were observed extending from the anode area to the cathode. They found no evidence that migration occurs with other metals under the practical conditions under which silver migration occurs. The rate of formation of silver deposits was found to be a function of relative humidity, insulating substrate, surface contamination, and de potential. For migration to occur at an appreciable rate it is necessary for water to be adsorbed on the insulating surface. These authors indicate at least one to two molecular layers. The relative humidity to attain this absorption is then a function of the chemical composition of the insulator and the type and amount of surface ionic contaminators. Little likelihood was expressed for migration below $30 \%$ R.H. Ceramics such as high purity alumina and steatite which possess low surface 
leakage at high humidity exhibited migration only at humidities near $100 \%$. With glass and mica migration occurred at lower humidities. Chaiken, Janney, Church, and McClelland $(9)$ found vast differences between different printed wiring board materials in their susceptibility to silver migration. A gold flash electroplated on silver foil was almost completely successful as a silver migration preventitive. Little positive protection was found for solder coatings on silver conductors. A silver-10\% Copper alloy showed reduced migration. Epoxy-glass and Teflon-glass substrates were found to support migration only at $85^{\circ} \dot{\mathrm{C}}$ and 95 to $100 \% \mathrm{R} . \mathrm{H}$. With phenolic paper or melamine-glass laminate migration occurred at lower temperatures in the same humidity range. For metals other than silver, only copper, tin and gold in decreasing order were found to migrate in detectable quantities. Lead, nickel, indium, aluminum, platinum, cadmium and rhodium did not migrate.

Separation is no remedy for filament growth as Williams and Hermann ${ }^{(10)}$ obtained complete silver migration across a $19 \mathrm{~mm}$ separation in 16 hours at or near $100 \%$ R.H. at room temperature and 135 volts. No visible migration was noted for $\mathrm{Pt}, \mathrm{Sn}, \mathrm{Cu}$, or $\mathrm{Sn}-\mathrm{Pb}$ solder. They observed silver migration at humidities as low as $75 \%$ in the presence of hygroscopic salts as surface contaminants.

As part of a study of voltage breakdown measurements on printed circuits Rainal, Landry and Lahti (ll) observed about half of the conductor pairs examined were realtively unaffected by a humidity change from 55 to 95\% $\mathrm{RH}$. For the remaining half a noticeable reduction in breakdown level was noted. They suggested that a slight 
amount of condensation occurred which produced the lowering of breakdown voltage.

Cole ${ }^{(13)}$ reported no silver migration in 2000 hours at room temperature and 80 to $100 \% \mathrm{R} . \mathrm{H}$. for silver and palladium silver conductors printed on alumina substrates with an applied de potential of 35 volts. Separations were .25 to $6.4 \mathrm{~mm}$. When a drop of water was placed between the conductors low resistance electrical failures occurred in 2 to 30 seconds. Similar failures were also obtained with patterns printed with gold-platinum, pure gold, moly-manganese, and moly-manganese with nickel plate. No material survived for more than approximately 15 minutes.

If one avoids $\mathrm{Sn}, \mathrm{Cd}, \mathrm{Zn}$ and $\mathrm{Ag}$ on $\mathrm{PWBS}$, is there any problem with filament growths? The answer is yes, there still is a problem. At Sandia Labotatories several instances are known of electronic assembly failures which could be attributed to low resistance paths being formed between conductors on PWBs at relatively low voltage. In these instances power was applied to the assemblies as they were being brought from $-54^{\circ} \mathrm{C}$ to $24^{\circ} \mathrm{C}$ and water condensate was observed on the boards. Black material was present between the conductors exhibiting a low resistance path. The electrical malfunction was reproduced by J. Ryberg by adding a drop of water to the space between the conductors and applying de potential.

From further investigations of the effect of deionized water drops placed between PWB conductors under dc potential in this laboratory, the following observations are listed below: 
1. All types of PWBs show filament growths which project from cathode to anode as shown in Figures 2,3 and $4^{\dagger}$. Conductor materials tested were bare copper, $\mathrm{Sn}-\mathrm{Pb}$ solder coated copper (obtained by either dipping and liquid leveling or by electroplating), bare nickel, and gold plated nickel. The boards were fabricated by pattern and panel processes at different suppliers using different types and sources of laminate.

2. The growths were produced with de potentials as low as 3 volts. Currents of up to 40 milliamps could be obtained after current bridging at higher voltages. After filament bridging occurred the potential could be lowered to 0.5 volt with a corresponding decrease in current as would be expected for electronic conductivity.

3. Filaments were friable and would frequently but not always rupture when the water evaporated or the board was mechanically disturbed. After drying some filaments showed resistances as low as 7000 ohms.

${ }_{\text {A } 3} 3$ minute film clip has been produced which demonstrates filament formation from a deionized water drop between solder coated copper conductors separated by $1 \mathrm{~mm}$ and an applied voltage of 10 volts. 
4. Filaments could be formed with deionized water on surfaces which displayed a high water contact angle and which had surface resistivities at $100 \% \mathrm{R} . \mathrm{H}$. of .01 to 10 teraohms.

5. Rate of the inhibition period and filament growth varied with potential, and surface contamination.

Anodic aluminum and chromium conductors did not form filaments. They form passive oxide films at the anode. When they were used as cathodic conductors with copper anodes, filaments were formed. Filaments formed more readily in the presence of ionic contaminates. Thus residual salts from plating; solder flux, and handing should be avoided whenever possible.

Dark deposits were produced between gold on nickel electroplated tabs as shown in Figure 5. The metal dissolved at the anode appears to have been reduced by ultra violet light or a reducing constituent from the laminate, or hydrogen prior to reaching the cathode. Condensing moisture conditions were reproduced in the laboratory by removing boards from a cold chamber and placing them in a desiccator jar maintained at 92 to $97 \%$ R.H. Under such conditions filaments could be grown from cathode to anode as shown in Figure 6 . For filament formation on typical PWBs it is only necessary that there be a de potential and a moisture drop or film which bridges the conductors. The closer the conductor spacing and the greater the water wetability of the separating dielectric, the less stringent the condensing conditions. Filaments have been grown on Teflon surfaces as shown in Figure 7 . 
Condensation and filament formation were also observed when a board in a dessicator jar at $97 \%$ R.H. was cooled from $65^{\circ} \mathrm{C}$ to $25^{\circ} \mathrm{C}$ while insulation resistance measurements were being made.

Enclosing a board in a polyethylene bag and taping around the emerging leads was effective in preventing moisture condensation on the board on transferring from a cold chamber to a humid atmosphere.

Polymer coatings should prevent filament formation by preventing a moisture film from bridging the conductors. This was in general found to be true for most separations on coated boards. If however there is a defect or scratch in the coating which exposes the conductor to moisture then a filament can form. Figure 8 shows filaments formed from intentional scratches on a urethane coated board. Figure 9 shows filaments formed at pinholes or defects in the coating. Filaments were also grown at defective spots on poly-xylylene coated boards.' The defective spots were located by immersing the board in distilled water with 20 to 40 volts applied and noting the spots where gas was evolved. It is not known if the defects were from voltage breakdown tests run earlier on the boards or if they originated during the coating and curing process. A nonbonding condition at the coating-laminate interface or the presence of hydroscopic contaminates which could cause blistering and moisture film formation from water diffusing through the coating could also give rise to filament formation. Although the probability of filament formation on coated boards is low, complete protection cannot be guaranteed unless the coating is applied and cured under conditions 
which generate no defective regions within the conductive pattern of the board.

\section{LEAKAGE RESISTANCE}

Nonfilament leakage currents can also arise from the surface and bulk ionic conductivity of the dielectric between conductors in high humidity environments. In order to compare the magnitude of this resistance with that observed during filament formation, available literature is reviewed and additional measurements from this laboratory are reported.

It is difficult to compare published surface resistance values as there is no set of standardized measurement conditions. There are apparent variations in equilibration time, differences between measurements at 92, 97, and 100\% R.H., differences in temperature and in the lengths and separations of conductors, and above all, the cleaning given the board prior to measurement or the application of a coating.

Field ${ }^{14}$ found rapid equilibration of de surface resistivity at 100\% R.H. for various polymeric and ceramic materials. The conductivity at the end of $I$ minute was within a factor of 10 of its equilibrium value which was usually attained within an hour. Rapid recovery was noted in going from $100 \%$ to $0 \%$ R.H. The equilibrium humidity values varied exponentially with humidity and at $100 \% \mathrm{R} . \mathrm{H}$. was considered a material property. Values ranged from 30 megohms to more than 20 teraohms. Hydrocarbon waxes and silicone had the highest resistivities. 
Sprengling(15) Investigating the surface resistivity of epoxyglass copper clad laminates and individual polymer resins, found contrary to Fields, that similar samples, equilibrated over a longer time interval, varied greatly in resistivity. Among a group of like samples there was a spread in the distribution of seven decades. He concluded that there was no single resistivity value characteristic of the given polymer surface at equilibrium with the humid ambient. Resistivities ranged from $10^{15} \mathrm{ohms} / \mathrm{sq}$ dry to $10^{8} \mathrm{ohms} / \mathrm{sq}$ at $100 \% \mathrm{R} . \mathrm{H}$. and $24^{\circ} \mathrm{C}$. Equilibration from humid to dry atmosphere was much more rapid than dry to humid. A series of coating resins used for conformal coating of printed circuit boards showed behavior essentially similar to the bare epoxy laminate. Exceptions were some fluorocarbon resins and some silicones which maintained high resistivity nearly indefinitely under humidity exposure. Glass surfaces dropped to a surface resistivity of about $10^{8} \mathrm{ohms} / \mathrm{sq}$ within minutes after exposure to a $100 \%$ R.H. ambient at $24^{\circ} \mathrm{C}$.

Williams and Hermann $(10)$ found the surface resistivity of uncontaminated high molecular weight polymers such as polyethylene, methyl methacrylate and Teflon to be higher than glazed or unglazed ceramics over a 14 day interval at $100 \%$ R.H. and room temperature. Equilibration typically occurred within l day. Rapid equilibration on changing to lower humidities was also obtained. Measuring potential was 400 volts.

All of the materials were very sensitive to contamination which tended to reduce them to a nearly common level of surface resistivity. Although beneficial, none of the alkyd, wax, or silicone 
coatings provided permanent protection and were similarly sensitive to contamination.

Wyble and Wolf ${ }^{(16)}$ measured the insulation resistance of uncoated and coated epoxy glass and polychlorotrifluoroethylene (PCTFE) PWBs over a 15 day interval at $95 \% \mathrm{R} . \mathrm{H}$. and $20^{\circ}$ to $71^{\circ} \mathrm{C}$. They concluded that uncoated boards perform better than coated boards, with the uncoated PCTFE boards being better than the uncoated epoxy-glass boards. There was a wide variation between acrylic, alkyd, polyurethane, epoxy and silicone coatings. Values ranged from $10^{1}$ to $10^{4}$ megohms. None of the coatings were able to maintain 1000 megohm minimum resistance on epoxy-glass boards in high humidity. Only a polyurethane was able to maintain 100 megohm resistance all the time. With coated epoxy-glass boards there was as much variability in resistivity between conductors on the same board as there was among different boards. There was little effect of spacing on insulation resistance or of the etching process used in board fabrication. The insulation resistance of all coated board combinations increased significantly within one hour after removal from high humidity. Several investigators found the protective capabilities of coatings to be dependent on the degree of coverage and the precleaning prior to coating. (17)(18)(19) Worthington $(20)$ measured the insulation resistance of various epoxy, silicone, styrene, urethane, acrylic, neoprene, phenolic-polyester, alkyd, natural rubber and teflon-filled polyurethane coatings using a copper comb pattern on type GE epoxy glass laminate. Insulation resistance changed from over $10^{12}$ ohms for dry environment to around $10^{5}$ ohms after 5 days at $85^{\circ} \mathrm{C}$ and $95 \%$ R.H. 
Subsequent tests were made on boards with components in the same environment for 10 days. Four component types indicated improved electrical performance, eleven indicated no significant change from uncoated boards. Two urethane and one acrylic coating showed superior performance. He concluded that there was no one coating currently known which would adequately protect all components under adverse temperature, humidity, and voltage stressing.

The room temperature, dry state, volume or bulk conductivity of a properly cured epoxy polymer laminate should not contribute appreciably to the conductivity between conductors on a PWB. As temperature is increased the bulk resistivity decreases exponentially and its contribution is increased, however most epoxies still have resistivities of the order of $10^{12}$ ohms at $100^{\circ} \mathrm{C}(21)$. If there is poor wetting of the glass weave in the laminate by the epoxy or voids or discontinuities are present between conductors, then non-surface laminate contributions in high humidity cannot be ignored.

Dahringer (22) observed electrolytic corrosion between copper wires wound on a glass mandrel and coated with DETA or polyamide cured epoxy. Currents of $10^{3}$ to $10^{-3}$ microamps were measured over a 15 day interval at $95 \%$ R.H. with a de potential of 45 volts. The observed current was a function of the cure history. Visible reduction products were observed at the anodic conductor in the case of room temperature cured specimens. Similar results were obtained with stainless steel and gold wires, including visible corrosion products. Elevated temperature cured specimens showed no evidence of corrosion. At very low humidities currents were less than $10^{-3} \mu$ amps even for the undercured specimens. 
Szedon (23) in evaluating protective coatings on screened gold conductor patterns on ceramic substrates found degradation at 500 volts in insulation resistance of polyurethane and diallylphthalate coatings after 21 days at $85^{\circ} \mathrm{C}$ and $95 \%$ R.H. Measurements were made at room conditions 15 to 60 minutes after the patterns were removed from the humidity chamber. White ${ }^{(12)}$ reported leakage currents of $10^{-7}$ amp when a 20 volt de potential was applied between titanium-gold conductors on high alumina ceramic substrates in a $98 \%$ R.H. nitrogen environment. With a drop of water spanning the conductors, the current increased to the milliamp range. Coatings were found to vary widely in their protective qualities. He attributed the protective qualities of a coating primarily to an interaction with the substrate surface rather than to the permeability characteristics of the coating material.

Insulation resistance measurements were made in this laboratory between solder coated copper conductors on type GH epoxy-glass laminate boards with and without polymer coating. Environmental conditions were 10 to $30 \%$ R.H. (dry) and 92 to 100\% R.H. (humid) at $24^{\circ} \mathrm{C}$. The board pattern contained 25 to $50 \mathrm{~mm}$ long conductor segments separated by 0.25 to $1.5 \mathrm{~mm}$. Either a Guildine teraohmmeter or Keithly $610 \mathrm{CR}$ meter was used for measuring resistance. Applied dc voltages were from 20 to 1000 volts. Humidities were maintained in desiccator jars with different aqueous solutions (24).

In the as-received dry state resistivities ranged from 100 to 1000 teraohms. There was considerable scatter between values for the same separations on similar boards, and it was difficult to achieve 
reproducible results in this resistivity range. The resistance between conductors did not correlate directly with separation distance. Resistivities measured after 72 to 144 hours at 92 to $100 \%$ R.H. were in the teraohm range. Filament formation was noted only when a moisture film was inadvertently formed on one board at 100\% R.H. When the boards were returned to dry condition after removal from the humidity container, most of the initial resistivity was regained within an hour.

Boards with poly-p-xylylene coating, 12 to $25 \mu \mathrm{m}$ thick, had higher dry resistivities than uncoated boards but in $100 \% \mathrm{R} . \mathrm{H}$. their values were similar.

Urethane coated boards 25 to $75 \mu \mathrm{m}$ thick, were similar to uncoated boards under both conditions. Boards encapsulated in glassmicroballoon-filled epoxy had resistivities 2 to 5 times higher than when the same boards were in the unencapsulated state. Boards which were enclosed in epoxy foam had slightly lowered resistivities after foaming. This decrease was not observed with boards foamed in urethane. After several days exposure to high humidity, the foamed or encapsulated boards had higher resistivities than bare boards in the same environment. For example, a $1.5 \mathrm{~mm}$ separation on a urethane foamed board showed only about one decade lowering of resistance, i.e., $10^{13}$ to $10^{12}$ ohms, from the dry condition to that after 12 days at 95\% R.H. After 24 hours at 15\% R.H. the initial dry resistivity was regained.

To provide known contamination, two uncoated boards were dipped in Alpha 611 then cleaned in trichloroethylene. After exposure to 
$97 \%$ R.H. at $24^{\circ} \mathrm{C}$ for 120 hours they showed an average resistance decrease of 4 to 5 decades. This trichloroethylene cleaning which is often used leaves a residue of one of the flux constituents (an organic amine hydrobromide) on the board surface. The

resistance decrease was much greater than observed with any of the other boards. After cleaning the boards with deionized water and 2propanol, the decrease in resistance from the dry state to that after 100 hours at $97 \%$ R.H. was less than a decade.

Filaments could be readily grown on this board by adding a drop of deionized water between conductors. The rapid change in resistivity after boards are removed from the humidity chamber indicates that most of the conductivity is on the insulator surface.

\section{CONCLUSIONS ,}

Whisker growth is a potential problem whenever PWBs with tin coatings are used or stored for any extended period regardless of the atmosphere. There are however many other protective metal coatings available for PWB conductors. With tin-lead or solder coatings which are frequently used on PWBs, whisker formation does not appear to be a significant problem provided no large external stresses are applied to the coatings.

Electromigration and electrolytic conductivity are of much greater concern to the electronic function of PWBs, especially when silver conductors are involved. Special concern must be exercised when electronic assemblies are operated under conditions in which moisture condensation can occur. Filament growths have been 
observed at relatively low de potentials from the cathodic to the anodic conductor with all of the typical PWB conductor metals. These growths can, but do not always, provide a residual leakage path between conductors when the moisture is evaporated. The presence of ionic contaminants on the board surface aid but are not essential to filament growth. Fingerprints, residues from board fabrication or solder flux, such as plating salts, and material leached from the laminate are likely sources for ionic contamination. Although these contaminants reduce the insulation resistance between conductors the reduction still leaves the resistivity in the 10 to 1000 megohm region. Filament bridges can give rise to much lower resistivity paths, often in the milliohm region. During filament growth, before bridging, resistivities are in megohm region.

To avoid filament bridges or excessive electrolytic leakage current it is essential that the board or assembly be maintained free from moisture condensation and as clean as possible. Enclosing the assembly in a polyethylene bag and taping around the emerging leads to prevent rapid water vapor transmission has been successfully used in thermal cycle tests in this laboratory.

Coatings are helpful in preventing filament formation but there is no assurance that the protection is complete unless the coatings are applied such that there are no defective or unbonded regions present. There is also no assurance that coatings will prevent electrolytic leakage currents but they do offer a barrier against finger prints, and other surface contaminants and vapor which could corrode and contaminate the circuit pattern. 
The time span for the measured leakage current in this study ranged from seconds to several days. There may however be long time effects which were not evaluated here. 
REFERENCES

1. H. I. Cobb, "Cadmium Whiskers," Monthly Rev. Am. Electroplaters Soc., 33, 28 (1946).

2. S. M. Arnold, "Repressing the Growth of Tin Whiskers," Plating, 53, $96(1966)$.

3. P. L. Key, "Surface Morphology of Whisker Crystals of Tin, Zinc, and Cadmium," Inst. Elec. \& Electronic Engr. Proc. 20th

Electronic Component Conf. May 1970 p. 155.

4. A. Jafri, "Fightning Whisker Growth in the Communications Industry," Plating, 60, 358 (1973).

5. S. C. Britton, "Spontaneous Growth of Whiskers on Tin Coatings: 20 Years of Observation," Trans. Inst. of Metal Finishing, 52, $95(1974)$.

6. V. K. Glazunova and N. T. Kudryavtsev, "An Investigation of the Conditions of Spontaneous Growth of Filiform Crystals on Electrolytic Coatings," J. Appl. Chem. USSR (Zhur Prikl Khim), 36, (3) 543, (1933).

7. J. F. Smith, "Whisker Growth on Electrodeposited Tin," Trans. Inst. Metal Finishing, 45, 9 (1967).

7A. C. Herring and J. K. Galt, "Elastic and Plastic Properties of Very Sma-1 Crystals," Phys Rev. 85, 1060 (1952).

8. G. T. Kohman, H. W. Hermance, and G. H. Downes, "Silver Migration in Electrical Insulation," Bell System Tech. Journal, 34, 1115 (1955).

9. S. W. Chaiken, J. Janney, F. M. Church and C. W. McClelland, "Silver Migration and Printed Wiring," Ind. \& Engr. Chem., 51, 229 (1959).

10. J. C. Williams and D. B. Hermann, "Surface Resistivity of NonPorous Ceramic and Organic Insulating Materials at High Humidity with Observations of Associated Silver Migration," IRE Trans. on Reliability and Control, 11-20 Oct. 1956.

11. A. J. Rainal, E. F. Landry, and J. N. Lahti "Voltage Breakdown of Fineline Flexible Printed Wiring," Proc. Ilth Elec. Insulation Conf. (IEEE), (1971), p. 228.

12. M. L. White, "Encapsulation of Integrated Circuits," Proc. IEEE, 57, 1610 (1969).

13. S. S. Cole, Private Communication, 1974. 
14. R. F. Field, "The Formation of Ionized Water Films on Dielectrics Under Conditions of High Humidity," J. Appl. Physics. 17, 318 (1946).

15. G. R. Sprengling, "Effects of Humidity on Polymer Surfaces," 1971 Conf. on Elec. Insulation and Dielectric Phenomena, p. 83.

16. C. W. Wyble and M. L. Wolf, "Do Coatings Really Protect Printed Circuits Under High Humidity Conditions?" Insulation, 15, 30 (May 1969).

17. H. G. Frankland and N. J. Sawyer, "How Good Are Your Printed Circuit Conformal Coatings," Insulation, 16, 29 (January 1970).

18. R. A. Dunaetz and A. W. Schwider, "Optimizing Conformal Coating Reliability and Cost for Military Electronics," SAMPE Journal, $\underline{8}$, 24, (July-August, 1972.)

19. C. J. Tautscher, "Causes and Prevention of Blisters in Conformal Printed Circuit Coatings," Insulation/Circuits, 18, 32 (June 1972).

20. D. G. Worthington, "Comparative Testing and Evaluation of Conformal Coating Materials and Processes," Proc. Il Elec. Insulation Conf. (IEEE) 1971, p. 217.

21. R. W. Warfield and M. C. Petree, "Electrical Resistivity of Polymers," SPE Transactions 1, No. 1, 80 (1961).

22. D. W. Dahringer, "Corrosion by Adhesives: Some Causes and Effects," Applied Polymer Symposia 19, 371, (1972).

23. I. R. Szedon, "An Approach for Evaluating Polymer Materials as Protective Coatings on Hybrid Microcircuits," IEEE Trans. on Parts, Hybrids, and Packaging, 10, 251 (1974).

24. A. Wexler and S. Hosegowa, "Relative Humidity-Temperature Relationships of Some Saturated Salt Solutions in the Temperature Range $0^{\circ}$ to $50^{\circ} \mathrm{C}$." J. Res. Nat. Bur. Stds. 53, 19 (1954). 


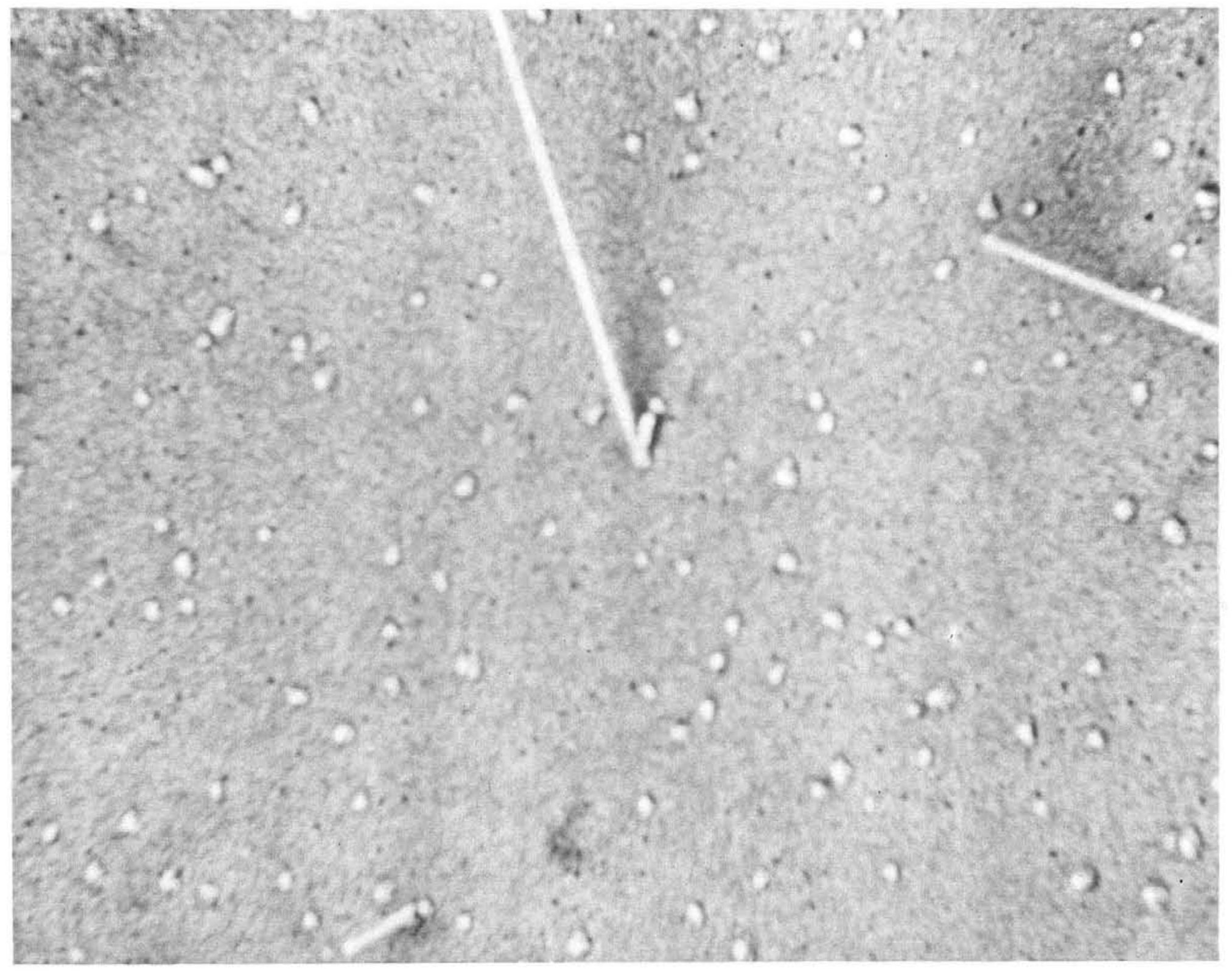

Figure 1 Tin Whisker growth on a tin plated surface. 


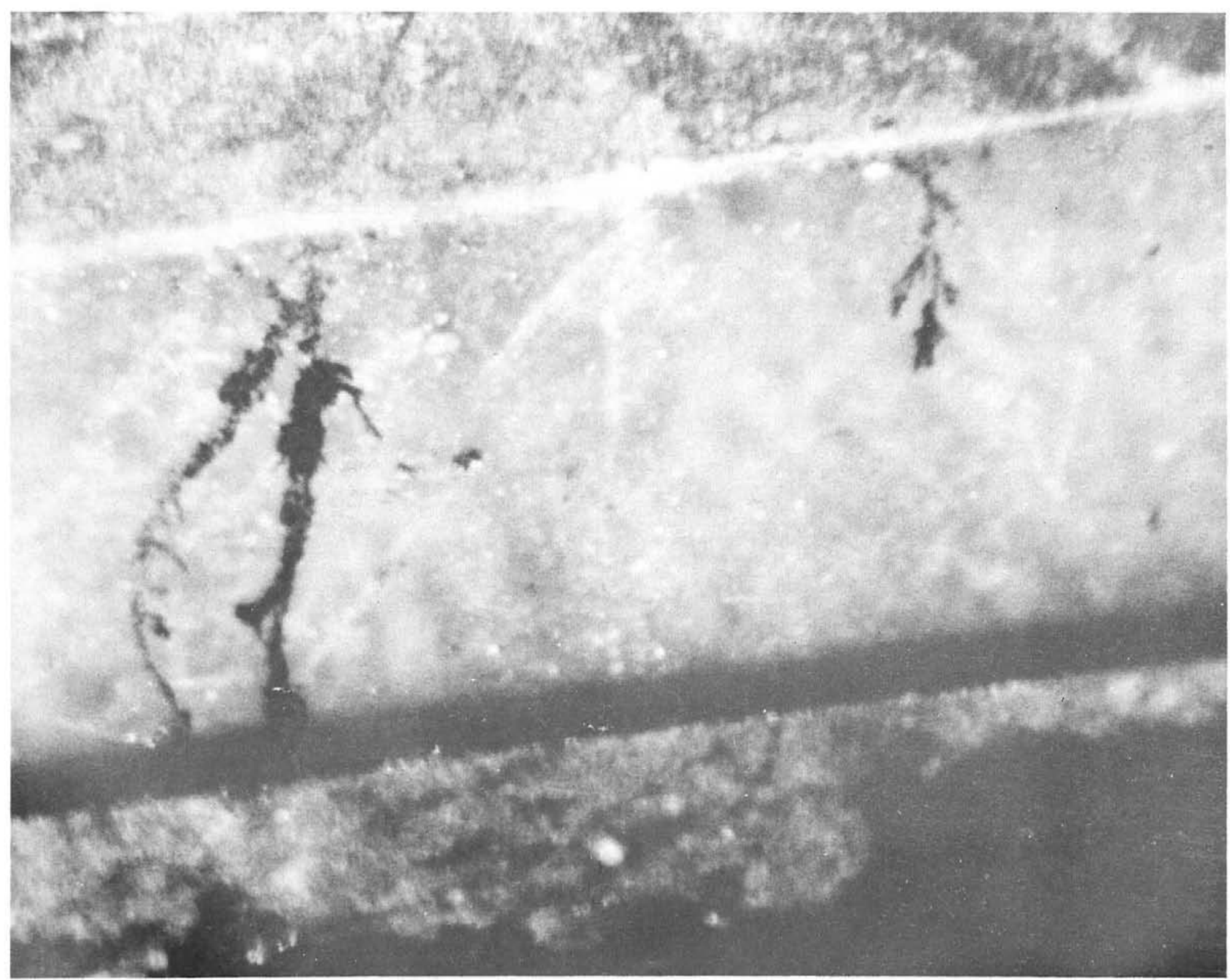

Figure 2 Filament growths formed between copper conductors $.75 \mathrm{~mm}$ apart on a PWB with a drop of deionized water and 3 volts de for 30 seconds. 


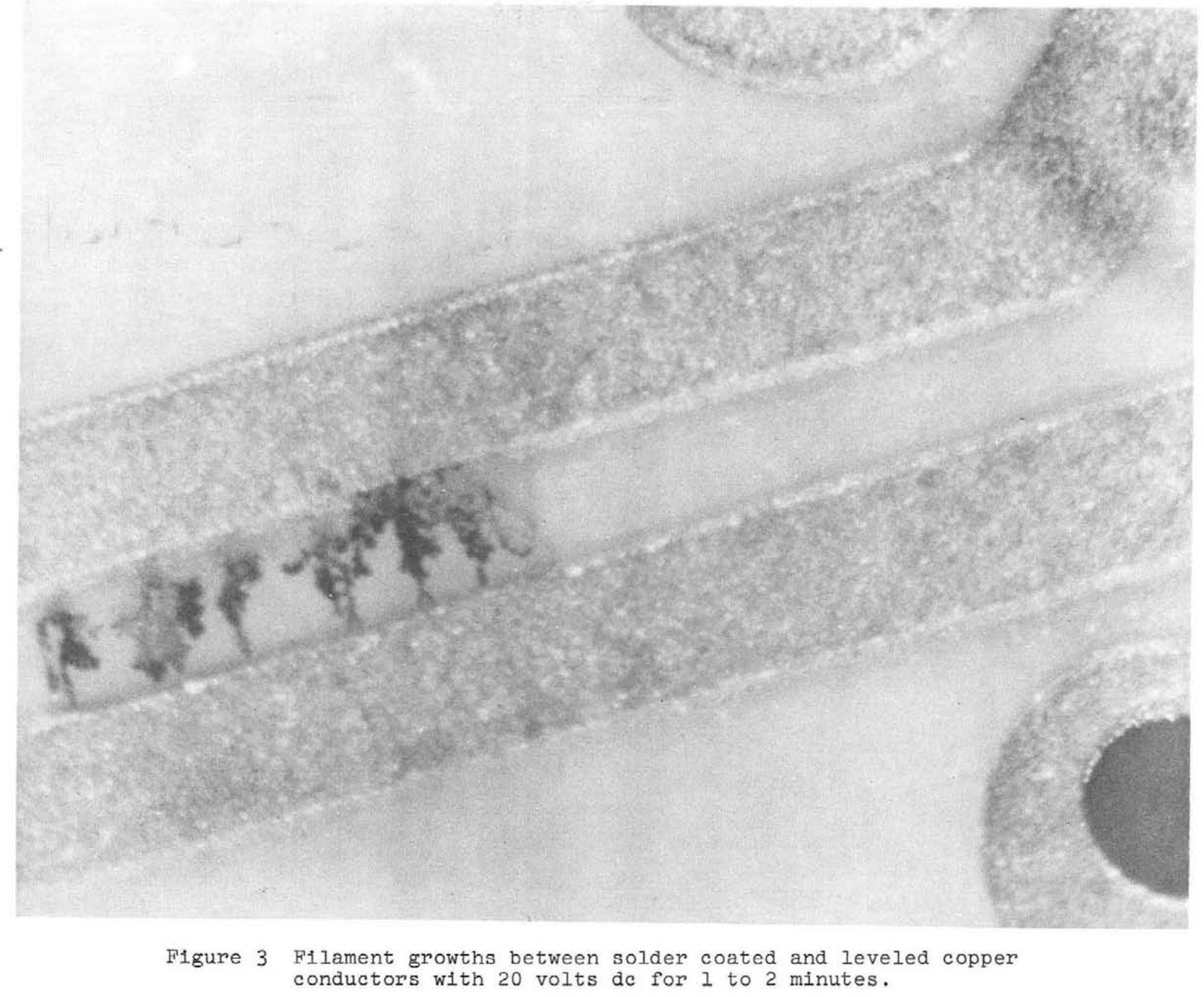
conductors with 20 volts de for 1 to 2 minutes. 


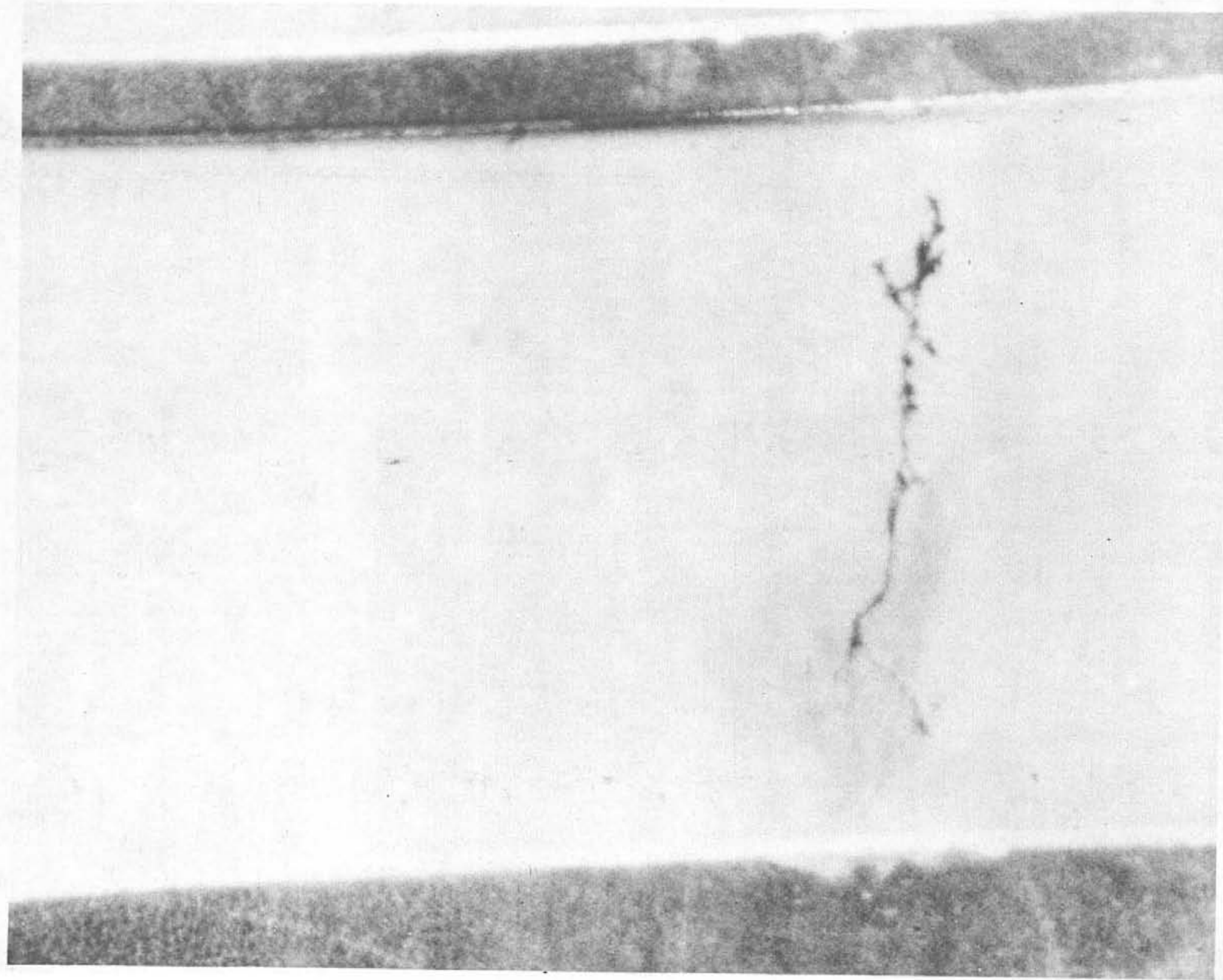

Figure 4 Filament growth interrupted before bridge was formed from cathode to anode over $5 \mathrm{~mm}$ separation. 


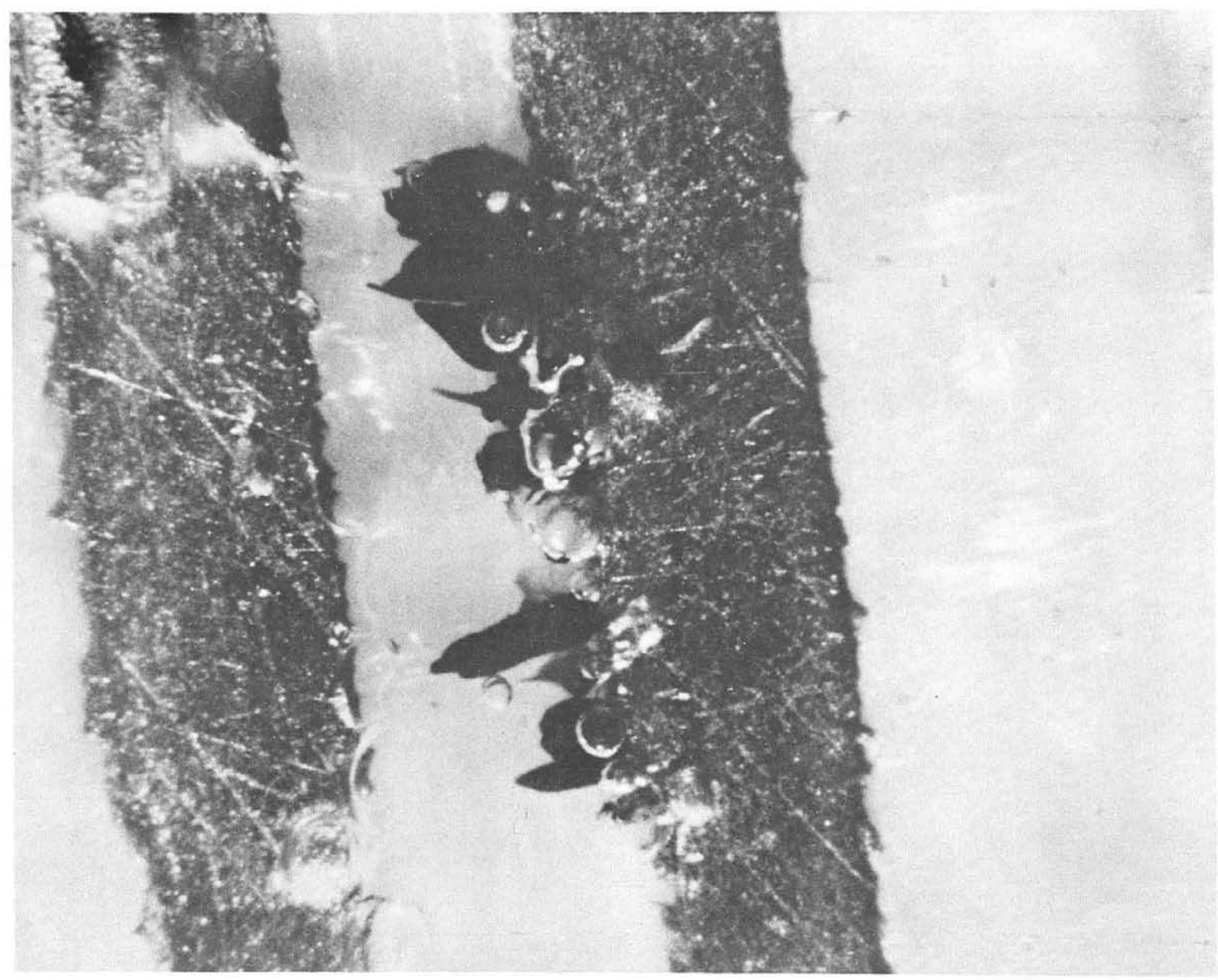

Figure 5 Growths formed between gold on nickel tabs on a PWB. 


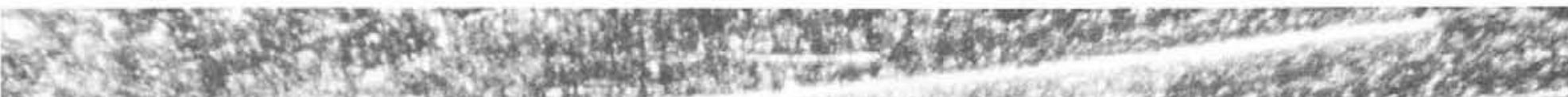

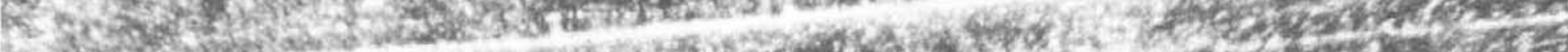

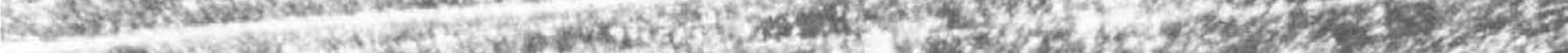

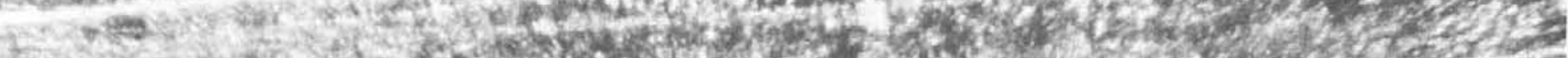

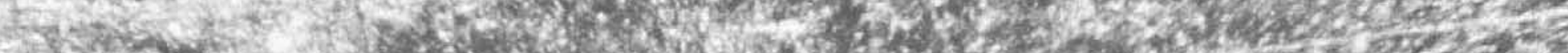

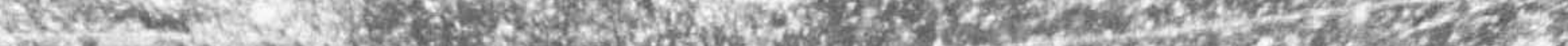

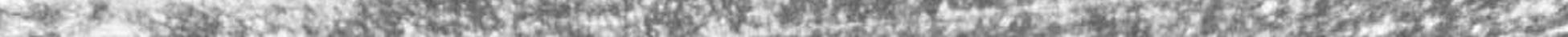

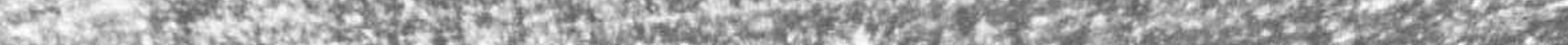
Whas and

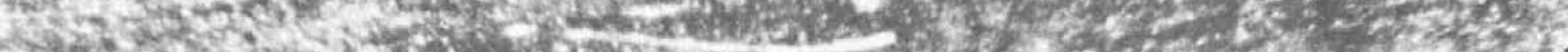

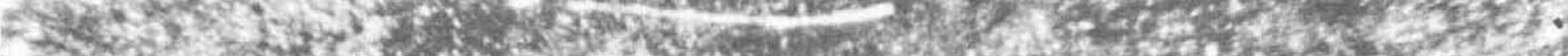

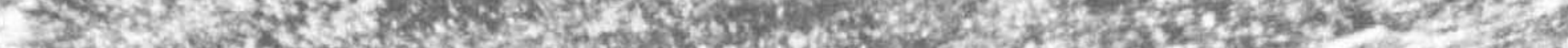

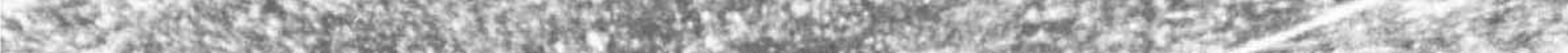

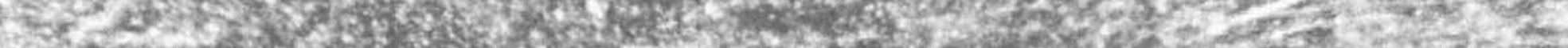

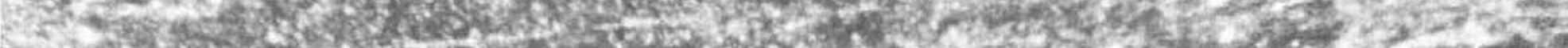

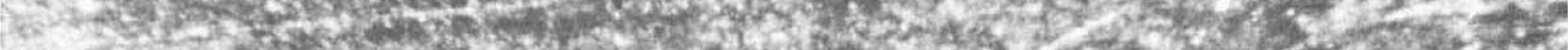

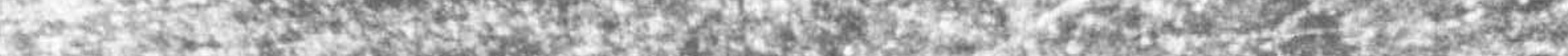

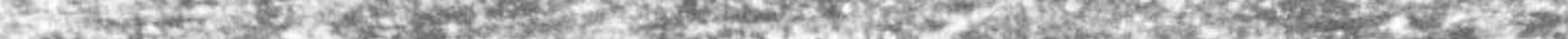

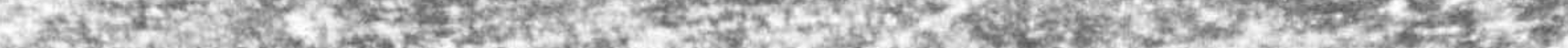

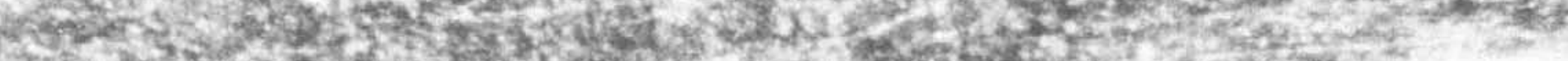

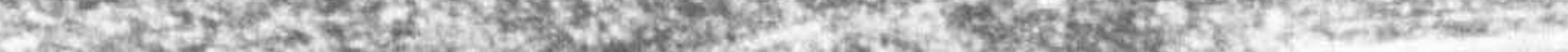
Haich

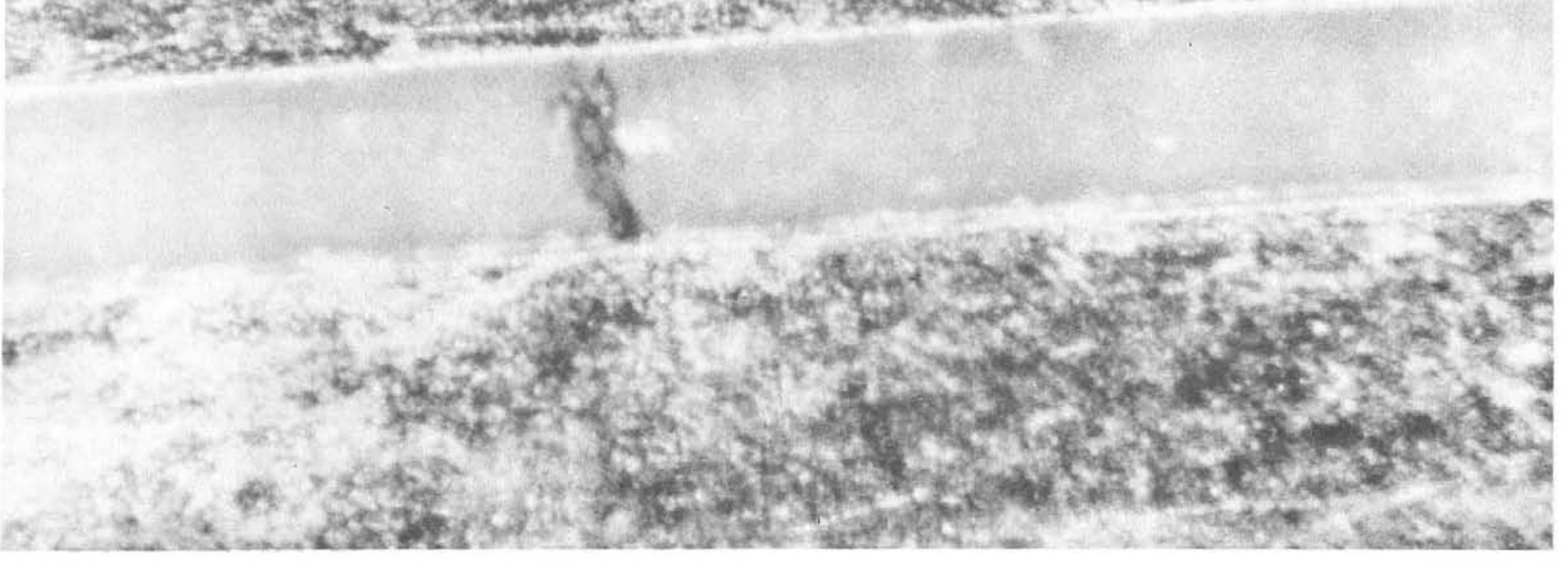

Figure 6 Filament grown on PWB under condensing moisture conditions with 20 volts, $.25 \mathrm{~mm}$ separation. 


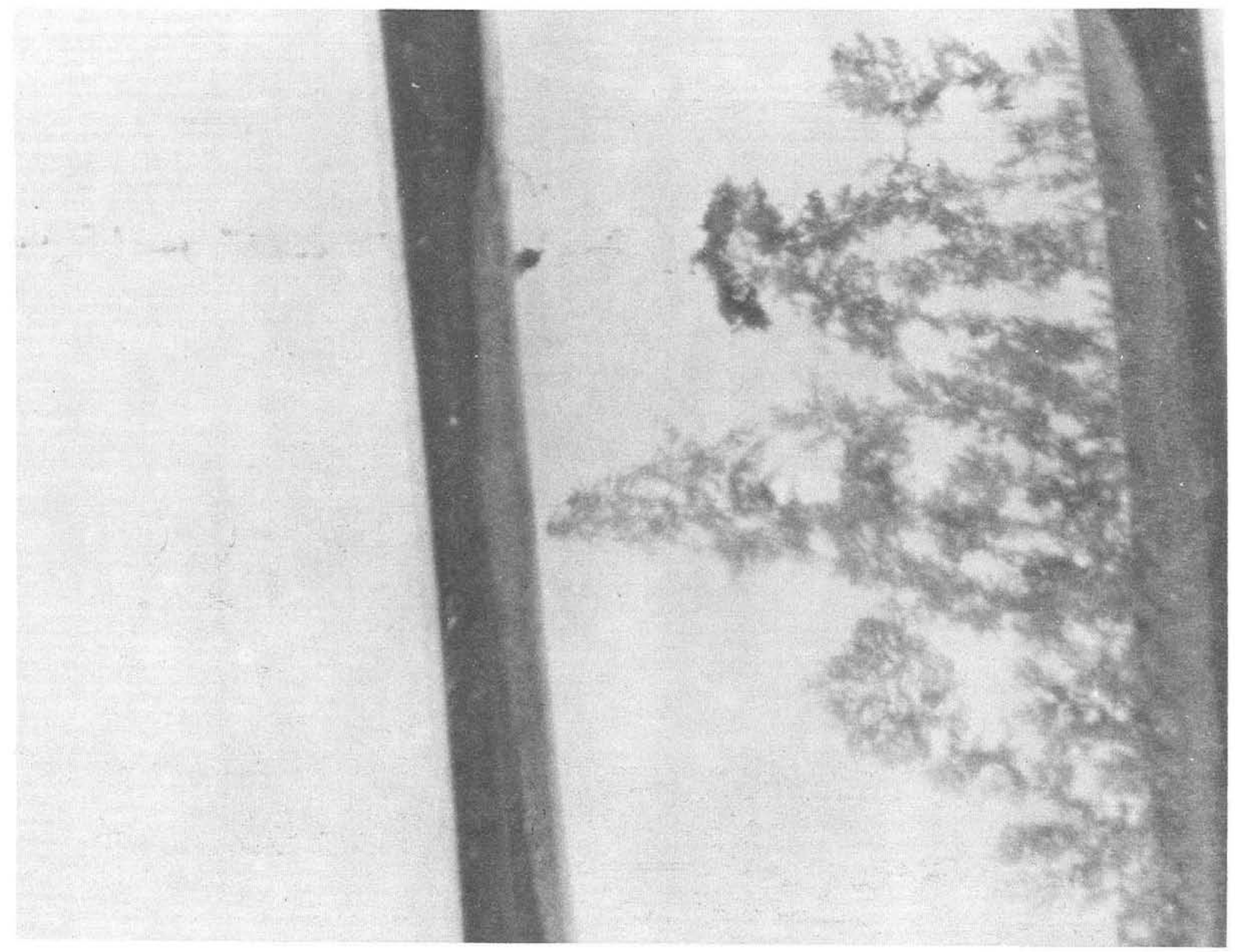




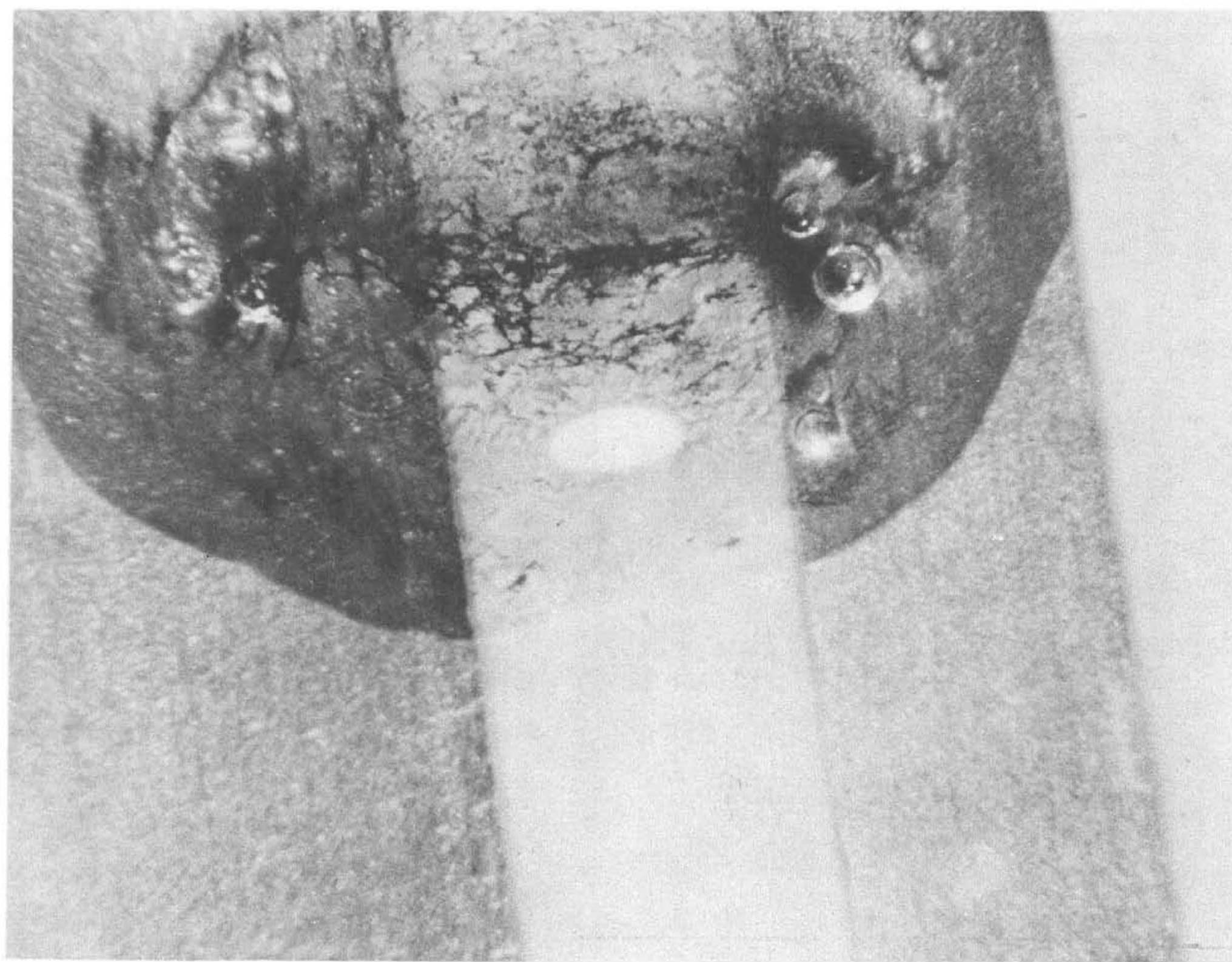

Figure 8 Filament growth from intentional scratches in urethane coated PWB, 20 volts, $1.25 \mathrm{~mm}$ separation. 


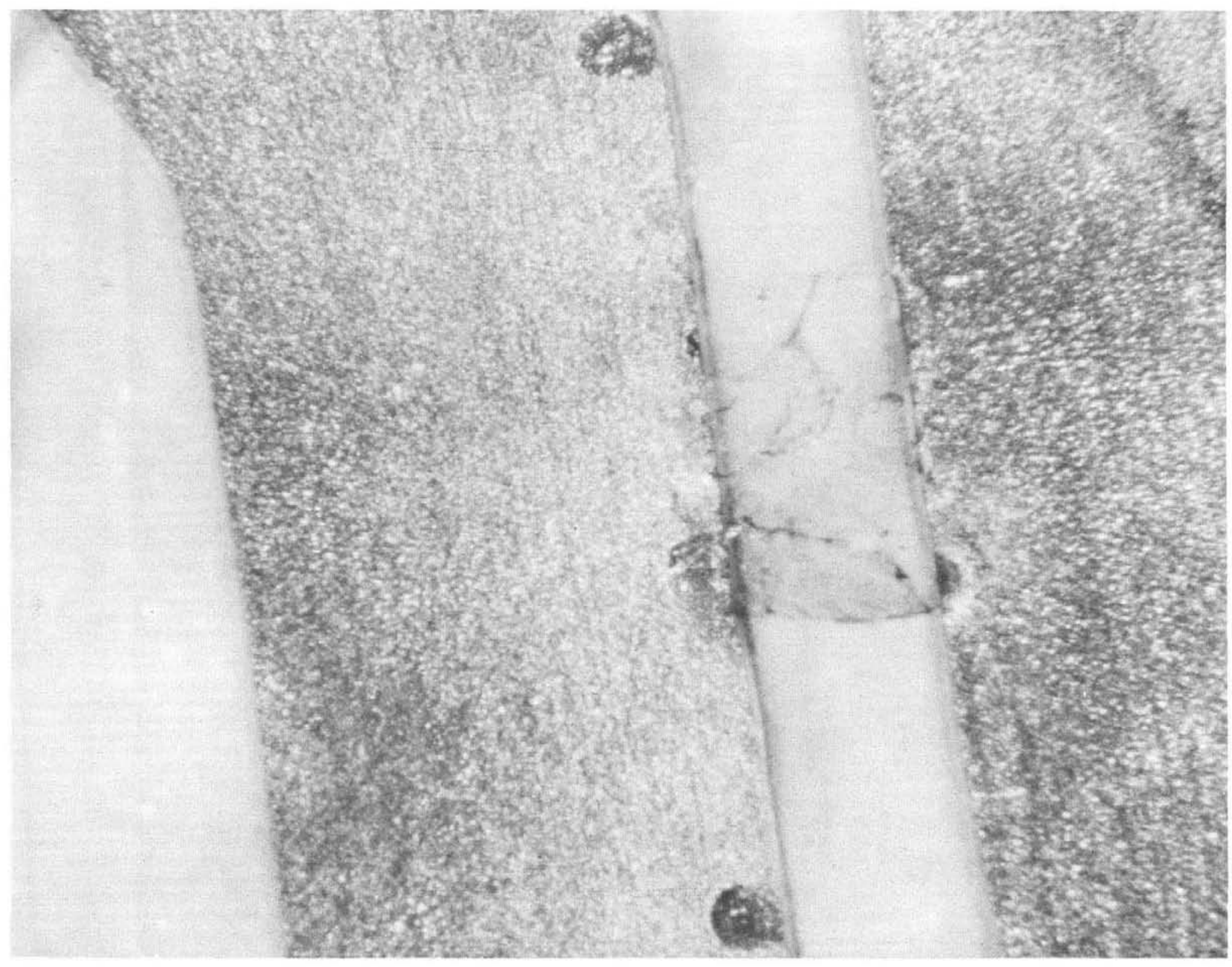

Figure 9 Filament growth from defects in urethane coating on PWB conductors, 20 volts, $0.38 \mathrm{~mm}$ separation. 
Distribution:

Lawrence Livermore Laboratory

P. 0. Box 808

Livermore, CA 94550

Attn: R. J. Hersey

The Bendix Corporation

Kansas City Division

P. O. Box 1159

Kansas City, MO 64141

Attn: J. L. Couchman, D/821

D. Jarboe, D/814

1247 J. C. Rehberg

2150 C. M. Tapp

2153 D. H. Weingarten

2153 C. W. Jennings (5)

8424 A. D. Andrade

3141 C. A. Pepmueller (5)

3151 W. L. Garner (3)

For ERDA/TIC (Unlimited Release)

8266 E. A. Aas (2)

ERDA/TIC (25)

(R. P. Campbell 3171-1) 